\title{
A FALA DO OUTRO: REPRESENTAÇÃO E ESTEREÓTIPO NA LITERATURA LUSÓFONA CONTEMPORÂNEA
}

\section{THE OTHER'S SPEECH: REPRESENTATION AND STEREOTYPE IN CONTEMPORARY LUSOPHONE LITERATURE}

\author{
Vanessa Castagna \\ Università Ca’ Foscari Venezia, Veneza, Itália \\ vanessa.r.castagna@gmail.com
}

\begin{abstract}
Resumo: Numa altura em que os estudos linguísticos agudizam a consciência da diversidade entre variedades nacionais da língua portuguesa - sobretudo entre PE (Português Europeu) e PB (Português Brasileiro) - regista-se na literatura produzida tanto em Portugal como no Brasil a ocorrência de várias tentativas de representação linguística do outro em diálogos entre personagens portuguesas e brasileiras. Se, por um lado, esse tipo de ocorrência descerra um interesse pela diversidade e a consciência de que essa diversidade existe, por outro lado, pelo menos uma parte dessas narrativas, ao apresentar o diálogo na diversidade, acaba por estereotipar as recíprocas identidades. Nessa perspetiva, a análise proposta cruza o domínio da sociolinguística e o da crítica literária, com o intuito de analisar a representação do contacto entre PE e PB em obras da literatura lusófona contemporânea, patenteando processos de normalização e estereotipização recorrentes.
\end{abstract}

Palavras-chave: Estereótipo Linguístico; Tradução Interlinguística; Português Europeu; Português Brasileiro; Ficção Contemporânea

\begin{abstract}
At a time when linguistic studies sharpen the awareness of the diversity between national varieties of the Portuguese language - especially between EP (European Portuguese) and BP (Brazilian Portuguese in the literature produced in both Portugal and Brazil there are several attempts of linguistic representation of the other in dialogues between Portuguese and Brazilian characters. If, on the one hand, this type of occurrence reveals an interest in diversity and the awareness that this diversity exists, on the other hand, at least part of these narratives, when presenting the dialogue in diversity, ends up stereotyping the reciprocal identities. From this perspective, the proposed analysis crosses the domain of sociolinguistics and that of literary criticism, in order to analyze the representation of contact between EP and $\mathrm{BP}$ in works of contemporary Lusophone literature, patenting processes of recurrent normalization and stereotyping.
\end{abstract}

Keywords: Linguistic Stereotype; Interlinguistic Translation; European Portuguese; Brazilian Portuguese; Contemporary Fiction 


\section{Introdução}

Nos últimos anos tem-se observado um crescente contacto e uma maior circulação de autores contemporâneos brasileiros em Portugal e portugueses no Brasil, devido inclusivamente a ações de política cultural promovidas pelos dois países, como ocorreu com o ano de Portugal no Brasil e do Brasil em Portugal (2012-2013), resultantes em edições diferentes nos dois países e por vezes com algumas diferenças a nível textual. Em particular, na maior parte dos casos os autores portugueses aceitam a adaptação ortográfica para o público leitor brasileiro, na medida em que o chamado Acordo Ortográfico (1990) não conseguiu ultrapassar a existência de duas normas ortográficas; mais raramente, há escritores, como é o caso de José Saramago, cuja obra, por determinação do próprio autor, continua a ser publicada no Brasil mantendo a ortografia em uso em Portugal. Pelo contrário, em Portugal as obras brasileiras costumam ser publicadas mantendo a sua convenção ortográfica.

Há, porém, uma grande variabilidade de situações, pelo que, por exemplo, Luiz Ruffato tem o seu romance Estive em Lisboa e lembrei de você publicado em Portugal sem alterações a não ser no título, que foi lusitanizado para Estive em Lisboa e lembrei-me de ti. Um caso muito mais atípico é o do autor brasileiro mais lido no mundo, ou seja, Paulo Coelho: a sua obra, de facto, sofre nas edições portuguesas não só uma adaptação ortográfica que implica, por vezes, a alteração, do título, mas observa-se uma verdadeira reescrita textual que abrange alterações na dimensão lexical e sintática, com consequências a nível de registo linguístico (CASTAGNA, 2016). Há, ainda, casos pontuais de edições revistas pelo próprio autor no meio-tempo que separa a edição no seu país e a edição posterior na outra margem do Atlântico, como no caso do romance $A$ chave de casa, de Tatiana Salem Levy, em que nos focaremos mais adiante.

Noutro plano, a comunicação entre as duas margens do Atlântico tem-se manifestado dentro da própria produção literária em língua portuguesa. Nas últimas décadas tem havido uma circulação bastante intensa de autores de língua portuguesa dentro da chamada lusofonia, de que são exemplos bastante conhecidos José Eduardo Agualusa e o angolano Ondjaki. O próprio projeto de circulação das suas obras por vezes leva os autores a escrever recorrendo a um padrão linguístico "globalizado". Em particular, o mesmo Agualusa, que conta com uma ascendência angolana, portuguesa e brasileira, afirma em relação ao seu português que ele

não é limitado por fronteiras políticas ou geográficas. O meu português não se restringe ao português de Angola, e muito menos às variantes do português de Portugal. O meu português é o português global, em toda a sua riqueza e exuberância. $\mathrm{O}$ meu projecto literário passa pela utilização desse português global. $\mathrm{O}$ Brasil tem 200 milhões de falantes, e inúmeras variantes da nossa língua. O português do Brasil preserva palavras que já despareceram em Portugal, e cria outras novas todos os dias. Tem uma enorme vitalidade. Como o português de Angola. Ambos vêm enriquecendo o português de Portugal. Os jovens portugueses, por exemplo, estão a apropriar-se de muitos termos do português de Angola. Todo esse movimento me fascina e me interessa. (LUCAS, 2015)

Como destaca Isabel Lucas (2015), a vivência das novas gerações de escritores, que viajam dentro do espaço da chamada lusofonia, muitas vezes acaba por refletir-se na sua produção literária:

Autores como Francisco José Viegas, José Eduardo Agualusa, Inês Pedrosa, Alexandra Lucas Coelho, Paulo José Miranda, Hugo Gonçalves, Matilde Campilho ou Valter Hugo Mãe e Gonçalo M. Tavares em crónicas, têm o Brasil - ou os muitos 'Brasis', como preferem chamar-lhe - como paisagem regular nas suas obras. E cada um apresenta razões muito pessoais para isso.

Talvez sejam mais os escritores portugueses que hoje vão para o Brasil e elaboram 
literariamente essa experiência nas suas obras, do que o contrário (LUCAS, 2015); porém, há casos em que também a estadia de escritores brasileiros em Portugal se reflete em livros, como se dá com o já mencionado Luiz Ruffato, cujo romance Estive em Lisboa e lembrei de você é precisamente o resultado de uma estadia em Portugal ao abrigo de um projeto denominado Amores Expressos, que lhe subsidiou a viagem.

Neste contexto de circulação de escritores dentro do espaço de língua portuguesa, é situação recorrente na literatura ficcional o contacto entre personagens pertencentes a países lusófonos diferentes e, precisamente nesse âmbito, é de destacar que a variedade linguística tem surgido com crescente frequência como elemento identificador de personagens representadas tanto em romances portugueses como brasileiros das últimas décadas, justificando uma análise exploratória dos efeitos produzidos em termos de representação do contacto entre português europeu $(\mathrm{PE})$ e português brasileiro (PB) na ficção lusófona contemporânea.

\section{Falas em português na ficção contemporânea}

A referência implícita à nacionalidade das personagens através da fala não é certamente uma novidade dos anos 2000 e, entre outros, pode-se referir o exemplo de Manuel Alegre, em Jornada de África, primeira obra ficcional do autor, editada em 1989, cujo narrador sugere a nacionalidade de uma personagem identificando-a como "aeromoça" em vez de "hospedeira", para sugerir que a naturalidade da mesma é dada a conhecer pelo sotaque:

\footnotetext{
Vem a hospedeira perguntar-lhe se toma um aperitivo. Tem os olhos verdes, sorri.

- Como é que se chama? - pergunta sem mais nem quê

- Bárbara - responde a aeromoça (ALEGRE, 1989, p. 29)
}

O ano de publicação deste romance (1989) é especialmente significativo, porque é também o ano em que, uma semana antes da queda do muro de Berlim - momento marcante da história do século XX, que decreta o fim da Guerra Fria - se constituiu em São Luís do Maranhão o Instituto Internacional da Língua Portuguesa por ocasião do encontro entre os chefes de Estado dos então sete países de língua oficial portuguesa, que já identificavam nessa mesma língua um instrumento privilegiado para a "difusão da criação cultural entre os povos que falam português e de projecção internacional dos seus valores culturais, numa perspetiva aberta e universalista" (CPLP, 1996). Esse encontro de 1 de novembro de 1989 foi o primeiro passo no caminho que levou à criação da Comunidade dos Países de Língua Portuguesa, a 17 de julho de 1996, por ocasião de um encontro entre chefes de Estado ocorrida em Lisboa.

A moda do ideário lusófono das últimas décadas tem vindo a incentivar um aproveitamento muito mais consistente deste tipo de recurso linguístico. Com efeito, em correspondência de um crescente interesse pela língua portuguesa a nível global, determinado pela sua projeção intercontinental, regista-se na literatura produzida tanto em Portugal como no Brasil a ocorrência de várias tentativas de representação linguística do outro em diálogos entre personagens portuguesas e brasileiras. Se, por um lado, esse tipo de ocorrência descerra um interesse pela diversidade e a consciência de que essa diversidade existe, por outro lado, pelo menos uma parte dessas narrativas, ao apresentar o diálogo na diversidade, acaba por estereotipar as recíprocas identidades.

Como já frisou Giorgio De Marchis (2008), há numerosos romances publicados em Portugal a partir dos anos 2000 que recorrem à variação diatópica da língua portuguesa para caracterizar as personagens e tornar patente a sua nacionalidade e cultura de origem. Giorgio de Marchis, em particular, nessa perspetiva chega a interpretar os romances $O$ ano em que Zumbi tomou o Rio (2002) do angolano José Eduardo Agualusa, Transatlântico (2004) do 
brasileiro Paulo Nogueira e Longe de Manaus do português Francisco José Viegas como sendo das primeiras manifestações literárias de um imaginário lusófono, diretamente ligado à instituição da CPLP, e patenteia em particular a caracterização linguística, com especial destaque para as diferentes variedades de português numa perspetiva diatópica mas também diastrática (sobretudo no caso do português brasileiro), e a exploração narrativa e estética que é feita em volta da diversidade linguística inerente ao português (ou, em volta da chamada "unidade na diversidade" $)$.

Nos últimos quinze anos, outras obras foram publicadas na esteira deste imaginário lusófono, rentabilizando de vária forma esse mesmo recurso da diversidade interna do português. Um exemplo que se pretende aqui apresentar é constituído pelo romance $A$ chave de casa de Tatiana Salem Levy. Trata-se de uma autora que entrelaça na sua história raízes familiares e cruza vários lugares. Nasceu em 1979 em Lisboa, onde a família de origem judia turca se encontrava exilada durante a ditadura militar brasileira. Regressou ao Brasil aos nove meses graças à Lei da Anistia, licenciou-se e doutorou-se no Rio de Janeiro, após uma estadia por motivos de estudo na França e nos Estados Unidos. A chave de casa é o seu primeiro romance, que publicou em 2007, e caracteriza-se por uma vincada matriz autobiográfica (a autora define-a uma "auto-ficção"). Graças a esta obra foi galardoada com o prémio São Paulo Literatura para melhor estreia literária e chegou a ser finalista do prêmio Jabuti em 2008. O romance foi publicado no mesmo ano no Brasil, pela Editora Record, e em Portugal, pela editora Livros Cotovia (na "coleção sabiá"), e nele ocupam uma posição relevante temas como o não-lugar, a procura de um lugar a que se pertença e a questão identitária, temas que, de alguma forma, também são pertinentes à questão da língua portuguesa hoje.

Já no fim de $A$ chave de casa surge o encontro entre a protagonista/narradora brasileira e um interlocutor português, que sugere algumas pistas de reflexão. Há elementos narrativos que deixam inferir à partida que se trata de um interlocutor português, pois o encontro dá-se em Lisboa. Eis quando pela primeira vez aparece "ele", personagem sem nome, que se contrapõe ao namorado/amante brasileiro ("você"): "Ele não sabia de nada, não sabia o que eu estava fazendo em Lisboa, por que estava lá. Devia imaginar que estivesse em férias." (LEVY, 2007, p. 191).

O encontro dá-se em frente ao café A Brasileira, quando a protagonista/narradora pede a um transeunte o favor de lhe tirar uma fotografia ao lado da estátua de Fernando Pessoa. Já as primeiras falas do diálogo parecem confirmar que "ele" é português, em virtude primeiramente do uso da forma de tratamento de segunda pessoa "tu". Essa marca acompanha sempre a personagem em questão. A primeira ocorrência surge no começo da conversa entre a protagonista/narradora e "ele", quando este lhe pergunta se está satisfeita com a foto, formulando a pergunta "O que pensas?" (LEVY, 2007, p. 191). Mas nas páginas que se seguem registam-se ocorrências análogas, como em: "mas, afinal, por que estás aqui?" (LEVY, 2007, p. 206), ou o imperativo na segunda pessoa singular e respetivos pronomes: "Toma, é para ti” (LEVY, 2007, p. 199), "Não tenhas medo" (LEVY, 2007, p. 207), só para mencionar alguns exemplos. No plano verbal, regista-se também a perífrase com o verbo

\footnotetext{
${ }^{1}$ Remete-se aqui para o "princípio da unidade na diversidade e da diversidade na unidade" retomado de Serafim da Silva Neto, que o aplica à situação linguística do Brasil: esse princípio, de forma devidamente circunstanciada, é adaptado em "unidade e diversidade da língua portuguesa" no capítulo dedicado ao "domínio atual da língua portuguesa" na gramática de Celso Cunha e Lindley Cintra (1985, p. 9). Todavia, o binómio que coaduna "unidade" e diversidade" tem sido revisitado ao longo das décadas, de um modo nem sempre isento de implicações ideológicas, inspirando inclusivamente o lema do VI SIMELP (Simpósio Mundial de Estudos da Língua Portuguesa) que se realizou em Santarém, em 2017: “A união na diversidade".Em relação ao romance de Francisco José Viegas, pode-se afirmar que "o mundo lusófono surge [...] como espaço fragmentado, diverso e plural, cuja unidade apenas existe não somente numa língua simultaneamente uma e diversa, mas no próprio conhecimento e reconhecimento dessa unidade e diversidade" (BARBEITA, 2013, p. 89).
} 
estar a seguido de infinitivo quando é "ele" quem fala, por exemplo na pergunta "É verdade ou estás a gozar?" (LEVY, 2007, p. 206).

A nível lexical, não há uma caracterização especialmente marcada da fala da personagem portuguesa, embora surjam alguns termos locais ao longo dos capítulos em que se desenrola o encontro entre as duas personagens. Em particular, refere a narradora "Pedimos duas imperiais" (LEVY, 2007, p. 192), dando certo exotismo à cerveja de pressão (ou ao "chope"). A narradora menciona, ainda, com certo gosto exótico nomes da doçaria portuguesa, por exemplo quando confessa: "gosto tanto que sou capaz de devorá-los mesmo de manhã: barriga de freira, pastel de nata, guardanapo, travesseiro, ninho de ovos, entre tantos outros" (LEVY, 2007, p. 206). Os nomes dos bolos transformam-se, a certa altura, em epítetos afetuosos, em particular no diálogo que se segue:

Ele pegou duas garrafas. Abriu uma e, segurando a outra, disse: toma, abre no Brasil e pensa em mim quando tomares. Agradeci, você é um amor. Tu é que és. E começamos a brincar: meu docinho de coco. Meu pastel de Belém. Meu chuchuzinho. Meu ninho de ovos. (LEVY, 2007, p. 210)

Nesta ficcionalização dialógica há elementos que podem parecer forçados, pouco naturais na fala comum, na oralidade. Assim, por exemplo, à pergunta "Tem um buquê de flores então", "ele" responde "Tampouco o tenho" (LEVY, 2007,p. 199). É possível que a preferência por "tampouco" em vez de "também não" dependa aqui do intuito de evitar a repetição com as respostas anteriores e a rima interna reiterada. Porém tanto o "tampouco" como a presença do pronome de complemento de objeto direto "o" em vez do objeto nulo dão uma representação estranhamente formal, monitorada, da fala da personagem portuguesa, que, tendo em conta o cotexto, não se pode interpretar como intencional e jocosa.

No polo oposto, há uma passagem onde o que, por inferência, supomos ser a fala da personagem portuguesa na verdade apresenta elementos que parecem típicos da variedade brasileira:

Façamos o seguinte, ele disse: passamos uma semana em cada cidade. Todo domingo à noite, vamos ao aeroporto e mudamos de continente. Assim não precisamos nos desfazer de nada, mantemos as duas casas, acho que é o mais justo. E o mais divertido, acrescentei. (LEVY, 2007, p. 203, sublinhado nosso)

De acordo com os turnos de fala, devemos supor que pelo menos uma das duas frases em que se inserem os sublinhados pertence a "ele", mas ambas apresentam características que não são do PE, em particular a expressão "todo domingo" em vez de "todos os domingos" ou "aos domingos", por exemplo, e o pronome solto entre os verbos precisar e desfazer, para além da regência do próprio verbo precisar, que em PE prevê a preposição de antes do infinitivo que se segue.

Para além de outros elementos que vão surgindo no romance em análise, decerto vale a pena destacar uma referência metalinguística. Nomeadamente, após revelar que nasceu em Lisboa e que foi para o Brasil aos nove meses, a protagonista comenta ironicamente: "Mas guardei o sotaque lisboeta, não percebes?" (LEVY, 2007, p. 206), em que a segunda pessoa verbal da pergunta sugere que a frase seja pronunciada imitando o sotaque de Lisboa.

Avaliando no conjunto os elementos apresentados, parece-nos poder afirmar que a ficcionalização do contacto dialógico entre falantes de PE e PB na obra examinada baseia-se principalmente nas divergências mais conhecidas entre as duas variedades de português, tais como as formas de tratamento $t u$ vs você e a seleção do infinitivo em vez do gerúndio na perífrase verbal com o verbo estar. Secundária e quase despercebida é a presença de outros elementos, que poderiam caracterizar de forma mimética a tipicidade do PE falado; os elementos selecionados, por seu lado, chegam a forçar a fala da personagem portuguesa, 
refletindo possivelmente a perceção que um brasileiro pode ter do PE: a este respeito, veja-se, em contexto de oralidade, o uso de tampouco em vez de também não, ou a explicitação do objeto direto pelo pronome em vez do mais comum objeto nulo.

Neste sentido, a representação do PE no romance de Tatiana Salem Levy parece afim à representação do $\mathrm{PB}$ em vários romances portugueses, ou seja, trata-se de uma representação pelo menos em parte estereotipada, uma vez que repete alguns clichês nem sempre verificados. Essa representação esterotipada, tantos nos romances portugueses como nos brasileiros, mesmo quando não cai propriamente no clichê, manifesta-se na busca de um exotismo ${ }^{2}$ complacente que aposta na acumulação de elementos de diferenciação interna. Nesse sentido, podem-se registar frases estranhantes para um português, atribuídas a personagens brasileiras, tais como "Vou botar isso na geladeira" (GONÇALVES, 2013, p. 21) ou "É muito maneira. Você viu as fotos de Angra que botei no Face?" (GONÇALVES, 2013, p. 22). No entanto, mais frequentemente a representação da fala do outro limita-se a reproduzir sempre os mesmos elementos de variação diatópica, negligenciando em regra geral outros, tais como as formas do imperativo, que no PB recriado pelos autores portugueses se limita às formas tradicionais (o chamado "imperativo verdadeiro" e formas supletivas) ${ }^{3}$, só para dar um exemplo concreto.

Um caso curioso é constituído pelo policial Longe de Manaus (2005) e Francisco José Viegas, que no Brasil viveu durante um período de quase dois anos antes de publicar esse romance. $\mathrm{O}$ autor esclarece numa nota que antecede o romance que

[a]o contrário das outras obras do Autor, este livro não segue as regras do Novo Acordo Ortográfico da Língua Portuguesa. Isto porque, publicado originalmente em 2005, Longe de Manaus foi escrito em duas ortografias distintas - portuguesa e brasileira - consoante os personagens e os cenários do livro. (VIEGAS, 2013)

Se, por um lado, é sabido que o Acordo Ortográfico de 1990 não esgotou as diferenças ortográficas portuguesa e brasileira (AZEREDO, 2008) e portanto a adoção das novas regras não implicaria a indiferenciação ortográfica entre $\mathrm{PE}$ e $\mathrm{PB}$, por outro a separação ortográfica nem sempre é rigorosa ao longo da obra ${ }^{4}$ e, de qualquer forma, a essência das diferenças entre as duas variedades de português em causa coloca-se noutros planos, visíveis a nível de escrita sobretudo no léxico e na sintaxe. Nestes planos, o autor não parece cair na tentação do exotismo, antes "abrasileira" com moderação quiçá excessiva algumas falas das suas personagens. Limitando-nos a uma passagem exemplificativa, podemos citar pelo menos a primeira parte de uma longa fala do delegado Osmar Santos:

É bem provável que não haja. E, depois, há Deus. Não devia haver Deus em mais nenhum hino porque Deus é brasileiro, como sabe - está na boca de todo o brasileiro. É propriedade nossa. Temos patente. As pessoas passam a vida falando de Deus e pedindo paz. O Brasil precisava de menos Deus e menos paz. Com essa paz toda fomos criando um humor trágico: rimos de tudo. Isso é bom, naturalmente, mas esconde outra coisa essencial. O riso abafa a tragédia, a desgraça e a corrupção dos ricos e dos poderosos. Os pobres de espírito é que não gostam do riso porque pensam que estão sempre rindo deles, mas não é verdade. O Brasil ri de si próprio

\footnotetext{
${ }^{2}$ Inês Pedrosa, autora de vários romances que têm o Brasil como pano de fundo ( $A$ eternidade e o desejo, 2007; Dentro de ti ver o mar, 2012; Desamparo, 2015) aponta precisamente para "o risco do exotismo e do pitoresco" (LUCAS, 2015) e declara atrever-se a brincar com o português brasileiro por sentir já uma relação muito próxima com o Brasil e os brasileiros; no entanto, confessa pedir ajuda a brasileiros para verificar e corrigir a fala das personagens brasileiras que introduz nos seus romances.

${ }^{3}$ Em relação ao uso variável de formas verbais do imperativo no português brasileiro veja-se, entre outros estudos de linguística sobre este tema, o trabalho de Marta Scherre et al. (2007).

${ }^{4}$ Por exemplo, pode-se referir a presença do acento diferencial típico do PE na primeira pessoa do plural do pretérito perfeito simples, que surge na fala da personagem brasileira Walmir (inventámos vs. inventamos, cfr. cap. 69).
} 
com grande classe, recuperando a honra perdida ao longo da história. Já viajou pelo Brasil? Eu viajo bastante, delegado Ramos. Há sempre criminosos do Amazonas em todo o lado. O país do riso não ri, delegado Ramos. (VIEGAS, 2013, cap. 46; sublinhado e negrito nossos)

Como se pode observar, neste trecho os únicos elementos marcantes para poder atribuir esta fala a uma personagem brasileira são os gerúndios evidenciados em negrito, ao passo que na restante formulação a fala poderia ser mesmo a de uma personagem portuguesa. Pelo contrário, não foram explorados outros elementos que poderiam surgir de forma mais especificamente típica do $\mathrm{PB}$, como um uso mais limitado do verbo haver com valor impessoal a favor de verbos como existir ou ter, a explicitação do sujeito (por exemplo, em "como sabe"), ou a omissão do artigo determinativo depois entre todo e o nome. De resto, já apontou ... que se ouvem, em Longe de Manaus, "duas vozes a 'duas línguas', a portuguesa de Jaime Ramos e a brasileira de Osmar Santos, duas visões de um eu e um outro que são simultaneamente o outro e o eu, mas que, deixando de ser duas, se entrelaçam e se dissolvem" (BARBEITA, 2013, p. 90).

Por outras palavras, na escrita de Francisco José Viegas deparamo-nos com uma situação que ocupa o polo oposto face ao exotismo, dentro da gama de possibilidades existentes, mas que também revela alguma superficialidade ao reduzir as diferenças entre PE e PB a uma questão de frequência de gerúndios, omissão do artigo determinativo antes de possessivo, ou pouco mais.

Em ambos os casos, podemos falar de uma representação da fala do outro que se baseia em estereótipos, que, na definição do sociolinguista italiano Gaetano Berruto, são "categorias preestabelecidas" que cristalizam "características rígidas e tendencialmente irreversíveis [...] principalmente implícitas, que são atribuídas a um objeto [...] com base numa generalização infundada (ou errada)" (BERRUTO, 2005, p. 111, tradução nossa). Além disso, como aponta Berruto, os estereótipos são resistentes a experiências que os contradigam, o que de facto parece ser o caso em análise, uma vez que a ficcionalização dialógica parece nortear-se principalmente por ideias preconcebidas, que nem a experiência prolongada dos autores no país em que se fala a outra variedade de português consegue fazer ultrapassar.

\section{Considerações finais}

A partir dos textos mencionados ao longo da análise proposta e que compõem uma amostra inicial com elementos significativos de reflexão, observa-se que as tendências predominantes na representação da fala de brasileiros por parte de autores portugueses e da fala de portugueses por parte de autores brasileiros na ficção contemporânea são de valorização do exotismo do outro ou, no polo oposto, de limitada reprodução da diversidade, que se concentra em poucos fenómenos de variação diatópica, entre os quais se destaca uma maior ocorrência de gerúndios.

Estas duas tendências, ainda que à partida sejam opostas, na verdade configuram-se como manifestações de uma propensão geral a reproduzir um estereótipo da fala do outro, independente da observação efetiva que os autores interessados tiveram a oportunidade de levar a cabo em função das suas experiências de viagem e de vida.

Tendo em conta os resultados da análise exploratória concretizada, pode-se considerar que um levantamento mais sistemático e alargado deste género de representação literária da diversidade interna do português poderá ser uma ferramenta útil para realizar um mapeamento do estereótipo linguístico existente entre falantes de diferentes variedades de português e contribuir para uma consciencialização maior a esse respeito. 


\section{Referências}

Alegre, Manuel. Jornada de África: Romance de amor e morte do alferes Sebastião. Lisboa: Dom Quixote, 1989.

Azeredo, José Carlos de (Coord.). Escrevendo pela nova ortografia: Como usar as regras do novo acordo ortográfico da língua portuguesa. São Paulo: Instituto Antônio Houaiss/Publifolha, 2008.

Barbeita, Magda Peixoto. Uma imagem é uma imagem é uma imagem: As narrativas de demanda de Francisco José Viegas. Dissertação de mestrado. Universidade do Porto: Faculdade de Letras, 2013.

Berruto, Gaetano. Fondamenti di sociolinguistica. Roma: Laterza, 2005.

Castagna, Vanessa. "Opere letterarie e best-seller tra adattamento ortografico e traduzione intralinguistica". In: Lupetti, Monica; Tocco, Valeria (A cura di). Giochi di specchi: Modelli, tradizioni, contaminazioni e dinamiche intercultural nei e tra i paesi di lingua portoghese. Pisa: Edizioni ETS, 2016, p. 495-504.

CPLP - Comunidade dos Países de Língua Portuguesa. Declaração constitutiva, 1996. Disponível em: https://www.cplp.org/id-3869.aspx. Acesso em: 20/06/2019.

Cunha, Celso; Cintra, Lindley. Nova gramática do português contemporâneo. Lisboa: Sá da Costa, 1985.

De Marchis, Giorgio. "The duck side of lusophony: O romance coelho-pato e a ficcionalização da lusofonia”. In: Kalewska, Anna (Org.). Diálogos com a Lusofonia. Warszawa: Studiów Iberyjskich i Iberoamerykańskich UW, 2008, p. 244-254.

Gonçalves, Hugo. Enquanto Lisboa arde, o Rio de Janeiro pega fogo. Lisboa: Casa das Letras, 2013.

Levy, Tatiana Salem. A chave de casa. Lisboa: Cotovia, 2007.

Lucas, Isabel. "Portugal e Brasil: orgulho e preconceito entre duas literaturas". Cultura-Ípsilon, [s.1], 3 de abril de 2015. Disponível em: https://www.publico.pt/2015/04/03/culturaipsilon/noticia/portugal-ebrasil-orgulho-e-preconceito-entre-duas-literaturas-1690391 Acesso em: 20/06/2019.

Ruffato, Luiz. Estive em Lisboa e lembrei-me de ti. Lisboa: Quetzal, 2010.

Scherre, Marta et al. "Reflexões sobre o imperativo em português". Revista DELTA-Documentação e Estudos em Linguística Teórica e Aplicada, São Paulo, v. 23, n. . 3, 2007, p. 193-241.

Viegas, Francisco José. Longe de Manaus. Lisboa: Porto Editora, 2013 [2005].

Recebido em: 20 de julho de 2019 Aceito em: 01 de novembro de 2019

Publicado em: Dezembro de 2019 